\title{
PENYULUHAN KEPADA IBU-IBU PKK MENGENAI SWAMEDIKASI DENGAN DETEKSI DINI TEKANAN DARAH DAN GULA DARAH DI KELURAHAN SIDOMULYO, SAMARINDA
}

\author{
Khalish Arsy Al Khairy Siregar1), Novia Misnawati Aisyah'1), Sylvan Septian Ressandy1), \\ Paula Mariana Kustiawan"1)
}

\author{
Corresponding author : Paula Mariana Kustiawan \\ E-mail : pmk195@umkt.ac.id
}

${ }^{1)}$ Fakultas Farmasi, Universitas Muhammadiyah Kalimantan Timur, Samarinda, Indonesia

Diterima 01 Juli 2021 2021, Direvisi 18 Juli 2021, Disetujui 19 Juli 2021

\begin{abstract}
ABSTRAK
Pandemi COVID-19 memberikan dampak pada pembatasan akses dan anjuran untuk berkegiatan di rumah. Hal ini menuntut peran ibu untuk lebih paham tentang swamedikasi. Swamedikasi merupakan upaya pengobatan sendiri yang pelaksanaannya dari mengenali gejala penyakit dan pemilihan obatnya dilakukan dengan inisiatif sendiri tanpa ke dokter atau tenaga kesehatan lainnya. Kegiatan pengabdian kepada masyarakat ini bertujuan untuk meningkatkan pengetahuan swamedikasi pada ibu-ibu PKK di Kelurahan Sidomulyo, Samarinda. Metode yang dilakukan pada kegiatan pengabdian kepada masyarakat ini adalah pembagian kuisioner di awal kegiatan yang diolah menjadi data, dilanjutkan dengan penyuluhan berupa presentasi interaktif tanya jawab dengan paserta, dan pengecekan kesehatan berupa pengukuran tensi dan gula darah. Kegiatan diakhiri dengan pembagian angket evaluasi kegiatan. Hasil kuisioner menunjukan sebanyak $73 \%$ mengetahui pengertian swamedikasi, namun hanya $23 \%$ peserta yang melakukan kegiatan swamedikasi di rumah. Setelah dilakukan edukasi, pengetahuan Ibu PKK tentang swamedikasi, menunjukan tingkat pemahaman baik. Sedangkan dari hasil pengecekan keseahatan, 77,7\% peserta memiliki nilai gula darah normal dan $89,6 \%$ peserta memiliki tekanan darah normal. Kegiatan mendapat tanggapan yang sangat baik dari peserta dan diharapkan untuk dilakukan kegiatan serupa secara berkala.
\end{abstract}

Kata kunci: swamedikasi; pemeriksaan kesehatan; penyuluhan.

\begin{abstract}
The COVID-19 pandemic has had an impact on access restrictions and recommendations for activities at home. This requires the mother's role to understand more about swamedikasi. Swamedikasi is a selfmedication effort whose implementation to recognize the symptoms of disease and choose the medicine by its own initiative without going to a doctor or other health workers. This community service activity aims to increase self-medication knowledge for PKK mothers in Sidomulyo Village, Samarinda. The method used in this community service activity are the distribution of questionnaires at the beginning of the activity which is processed into data, followed by counseling with presentation and Q\&A sessions, and medical check up by measuring blood pressure and blood sugar. The activity ended with the distribution of evaluation questionnaires. The results of the questionnaire showed that $73 \%$ knew the meaning of self-medication, but only $23 \%$ of participants carried out self-medication activities at home. After the education was carried out, PKK mother's knowledge of self-medication showed a good level of understanding. Meanwhile, from the results of medical check up, $77.7 \%$ of participants had normal blood sugar values and $89.6 \%$ of participants had normal blood pressure. The activity received a very good response from the participants and similar activities expected will be held periodically.
\end{abstract}

Keywords: self-medication; medical check up; counseling.

\section{PENDAHULUAN}

Pandemi COVID-19 merupakan kondisi darurat masyarakat dunia yang mengalami perkembangan sangat cepat dalam penularan virusnya. Ketidaksiapan layanan kesehatan menghadapi lonjakan pasien menuntut masyarakat untuk lebih bijak dalam memahami upaya pencegahan yang efektif. Himbauan untuk 
diam di rumah dalam rangka menurunkan penyebaran penyakit dan juga karantina wilayah dalam skala besar (Setiati \& Azwar, 2020),

$$
\text { Swamedikasi merupakan upaya }
$$

pengobatan sendiri yang pelaksanaannya dari mengenali gejala penyakit dan pemilihan obatnya dilakukan dengan inisiatif sendiri tanpa ke dokter atau tenaga kesehatan lainnya. Swamedikasi ini dapat dijadikan alternatif pada masyarakat untuk mengurangi biaya pengobatan dengan pengetahuan pengobatan yang didapat dari iklan, brosur maupun penyuluhan oleh tenaga kesehatan. Sehingga masyarakat tidak perlu ke dokter untuk mengobati penyakit-penyakit ringan seperti demam, batuk, dan influenza (Y. Nita et al., 2008; Restiyono, 2016). Terutama di masa pandemi COVID-19 ini. Namun, dalam pengobatan secara swamedikasi ini perlu adanya pengetahuan mengenai cara penggunaan obat yang benar dan tepat sesuai dengan pedoman yang ada.

Pengobatan tepat pasien, tepat indikasi, tepat obat dan tepat dosis merupakan sebuah syarat untuk tata laksana swamedikasi. Disamping itu juga perlu adanya antisipasi dalam untuk mencegah efek samping untuk tidak menimbulkan keluhan lainnya. Penerapan swamedikasi hanya berlaku terbatas pada golongan obat bebas, obat bebas terbatas dan obat wajib apotek atau (OWA). Pengunaan obat yang sesuai dan benar sesuai golongannya dapat membantu masyarakat dalam pengobatan swamedikasi, sehingga tidak terjadinya efek samping ataupun interaksi obat yang tidak diinginkan (Candradewi \& Kristina, 2017).

Masyarakat juga perlu mengetahui penggolongan obat yang boleh diperjual belikan di apotek, toko obat, dan warung sekitar. Karena tidak semua obat dapat di jual oleh warung atau toko obat terdekat seperti obat golongan keras, psikotropika, dan narkotika tidak boleh dijual di warung atau toko obat terdekat (Restiyono, 2016). Salah satu obat yang sering dijual sembarangan adalah Antibiotik. Antibiotik merupakan obat yang digunakan untuk infeksi bakteri pada penyakit-penyakit tertentu yang penggunaannya harus dengan resep dokter. Namun, sebagian masyarakat masih menggunakan antibiotik secara sembarangan dengan alasan agar cepat sembuh dan sering pula ditemukan antibiotik dijual bebas di warung dan toko obat (Restiyono, 2016; Yarza et al., 2015).

Edukasi tentang swamedikasi serta penggolongan obat sangat diperlukan masyarakat, terutama di kondisi pandemi yang mengharuskan kita untuk berkegiatan di rumah saja. Terutama peran ibu dalam mengurus keluarga ketika salah satu anggota keluarga mengalami sakit, namun masih bisa dilakukan swamedikasi. Perlunya masyarakat juga memahami bagaimana penggunaan obat yang benar, efek samping obat, kontra indikasi, penyimpanan obat, dan tanda-tanda kerusakan sediaan obat secara fisika agar dalam pengobatan secara swamedikasi tidak menimbulkan penyakit lain yang dapat membahayakan jiwa.

Selain itu juga dilakukan pengecekan tekanan darah dan gula darah. Semakin tua manusia maka semakin rentan juga berbagai penyakit menyerang, perlu adanya langkah antisipasi dengan cara melakukan check-up rutin diantaranya dengan mengecek tekanan darah dan glukosa darah, dimana keduanya merupakan langkah awal untuk mengetahui tingkat kesehatan manusia. Diabetes Melitus merupakan salah satu penyakit yang disebabkan oleh polah hidup yang tidak sehat dan menyebabkan penyakit bisa mengalami dampak kronis yang terjadi ketika pankreas tidak cukup menghasilkan insulin. Insulin merupakan hormon yang berperan untuk mengatur gula darah (Saputra et al., 2018). Begitu juga pada Hipertensi, dimana hipertensi merupakan keadaan seseorang mengalami peningkatan tekanan darah diatas normal (Endang, 2014).

Berdasarkan hal tersebut, perlunya dilakukan edukasi berupa penyuluhan mengenai swamedikasi kepada ibu-ibu kelompok PKK dan pengecekan kesehatan. Hal tersebut juga untuk mencegah pengobatan swamedikasi yang tidak sesuai dengan kriteria yang menyebabkan penggunaan obat tidak rasional. Sehingga peran ibu, sangat menentukan dalam penanganan swamedikasi yang tepat. Pengecekan kesehatan juga dilakukan untuk mengetahui tingkat kesehatan ibu-ibu PKK sehingga bisa mengatur pola makannya sebagai pencegahan penyakit penyerta (komorbid) di situasi pandemi ini.

\section{METODE}

Kegiatan pengabdian masyarakat ini dilakukan kepada kelompok ibu-ibu PKK Kelurahan Sidomulyo di halaman parkir (ruang terbuka), Kantor Kelurahan Sidomulyo Kota Samarinda, Jalan Marskal Muda Abdurachman Saleh No.1 RT.40 pada tanggal 9 Juni 2021. Sebelumnya telah dilakukan survei lokasi dan perijinan untuk melakukan kegiatan pengabdian di kelurahan tersebut.

Penyuluhan dilakukan dengan beberapa 
tahapan. Di awal kegiatan, dilakukan pembagian kuisioner untuk mengetahui karakteristik peserta dan tingkat pengetahuan yang kemudian dijadikan data. Dilanjutkan penyuluhan berupa presentasi ilmiah dan pembagian pamflet kepada peserta kegiatan. Presentasi dilakukan secara interaktif dengan kegiatan tanya jawab.

Kegiatan dilanjutkan dengan pengecekan kesehatan berupa pengecekan gula darah dan tekanan darah menggunakan alat Glukometer dan Sfigmomanometer. Pemeriksaan awal dimulai dengan melakukan wawancara identitas dan riwayat penyakit peserta penyuluhan, kemudian dilakukan pemeriksaan gula darah sewaktu dan tekanan darah sesuai urutan absensi kegiatan.

Pembagian angket evaluasi dibagikan pada akhir kegiatan ini. Hal tersebut untuk mengetahui tingkat pemahaman peserta penyuluhan dan respon terhadap keseluruhan kegiatan pengabdian kepada masyarakat yang telah dilakukan.

\section{HASIL DAN PEMBAHASAN}

Karakteristik peserta penyuluhan dapat dilihat pada tabel di bawah ini.

Tabel 1. Karakteristik Peserta Penyuluhan

\begin{tabular}{lcc}
\hline \multicolumn{1}{c}{ Karakteristik peserta } & $\mathbf{N}=\mathbf{3 0}$ & $\%$ \\
\hline Usia & & \\
\hline $18-59$ & 29 & $97 \%$ \\
\hline$\geq 60$ & 1 & $3 \%$ \\
\hline Pendidikan terakhir & 1 & $3 \%$ \\
\hline Sekolah Dasar (SD) & 3 & $10 \%$ \\
\hline Sekolah Menengah Pertama & 19 & $63 \%$ \\
(SMP) & 7 & $23 \%$ \\
\hline Sekolah Menengah Atas (SMA) & & \\
\hline Perguruan Tinggi & 5 & $17 \%$ \\
\hline Pekerjaan Ibu & 1 & $3 \%$ \\
\hline Pegawai negeri (PNS) & 1 & $3 \%$ \\
\hline Pegawai swasta & 21 & $70 \%$ \\
\hline Pedagang & 2 & $7 \%$ \\
\hline lbu Rumah Tangga & & \\
\hline Tidak tahu &
\end{tabular}

Hasil kegiatan pengabdian kepada masyarakat pada awal kegiatan adalah informasi karakteristik peserta penyuluhan Berdasarkan Tabel 1., peserta penyuluhan berada pada kelompok usia yang mendominasi 18-59 tahun (97\%). Pendidikan terakhir SMA (63\%). Pekerjaan ibu sebagian besar adalah ibu rumah tangga (IRT) (70\%).

Pemilihan karakteristik berdasarkan usia adalah karena usia merupakan lamanya seseorang telah hidup sejak manusia tersebut dilahirkan, kemudian dengan bertambahnya usia maka daya tanggap dalam menerima informasi juga meningkat. Dalam usia produktif tingkat kematangan dan kekuatan seseorang dalam berpikir dan bekerja sangat baik. Kemudian pada usia lanjut memiliki pengetahuan dan pengalaman yang lebih banyak dibandingkan usia muda, sehingga dapat lebih siap dalam menghadapi suatu hal yang baru. Sedangkan pengaruh pendidikan terakhir juga mempengaruhi penerimaan informasi yang akan diberikan. Berdasarkan pendidikan dapat dikatakan bahwa seseorang yang berpendidikan dapat lebih mudah menerima informasi, dikarenakan selalu menerima pembelajaran atau informasi yang baru dan belajar dari suatu masalah. Jenis pekerjaan akan mempengaruhi bagaimana orang tersebut menjalankan kehidupannya dan cara memperoleh kebenaran suatu informasi yang didapatkan. Hal ini akan mempengaruhi penerimaan peserta terhadap edukasi yang akan disampaikan saat kegiatan penyuluhan.

Tabel 2. Pengetahuan Mengenai Swamedikasi

\begin{tabular}{lcc}
\hline \multicolumn{1}{c}{ Pengetahuan } & $\mathbf{N}=\mathbf{3 0}$ & $\%$ \\
\hline Definisi Swamedikasi & & \\
\hline Benar & 22 & $73 \%$ \\
\hline Salah & 5 & $17 \%$ \\
\hline Tidak tahu & 3 & $10 \%$ \\
\hline \multicolumn{2}{l}{ Hal yang dilakukan ketika sakit } \\
\hline Membiarkan sampai sembuh & 0 & $0 \%$ \\
\hline Mengobati sendiri & 7 & $23 \%$ \\
\hline $\begin{array}{l}\text { Pergi ke dokter di } \\
\text { puskesmas/rumah sakit/klinik }\end{array}$ & 23 & $77 \%$ \\
\hline
\end{tabular}

Berdasarkan Tabel 2., peserta penyuluhan yang mengetahui definisi swamedikasi adalah sebesar $73 \%$ dan hanya $23 \%$ yang melakukan pengobatan sendiri (swamedikasi). Hal ini kemungkinan disebabkan oleh beberapa faktor yaitu faktor sosial ekonomi, gaya hidup, kemudahan memperoleh obat, kesehatan lingkungan dan kesehatan masyarakat, serta ketersediaan obat baru. (Abdulkadir \& Thomas, 2019).

Diperkuat dengan pendapat (Husni \& Rahayu, 2020; Kurniasih et al., 2020; Yusuf et al., 2021) bahwa adanya hubungan yang cukup signifikan antara umur dan pendidikan, pekerjaan terhadap tingkat pengetahuan masyarakat dalam tindakan swamedikasi, contohnya pada penyakit diare. Pengaruh lingkungan juga memiliki peran penting dalam perilaku swamedikasi. Media sosial atau iklan televisi dapat memberikan 
pengaruh terhadap perilaku swamedikasi. (Mardiati et al., 2021) dan (Dianawati et al., 2008), menyatakan bahwa ada pengaruh signifikan persepsi iklan obat yang bisa mengindikasi penyimpangan perilaku swamedikasi. Oleh karena itu, penyuluhan tentang swamedikasi yang benar sangat diperlukan.

\section{Penyuluhan tentang Swamedikasi}

Kegiatan penyuluhan dilakukan selama 2 jam dan diikuti sebanyak 30 peserta. Kegiatan dibuka oleh sambutan dan perkenalan ketua kelompok ibu PKK, Kelurahan Sidomulyo (Gambar 1.). Materi penyuluhan yang diberikan berupa presentasi interaktif tentang pengertian swamedikasi, tahapan yang harus dilakukan untuk melakukan swamedikasi yang benar, penggolongan obat paten dan obat herbal yang bisa digunakan dalam swamedikasi. yang disertai sesi tanya jawab oleh peserta penyuluhan (Gambar 2.).

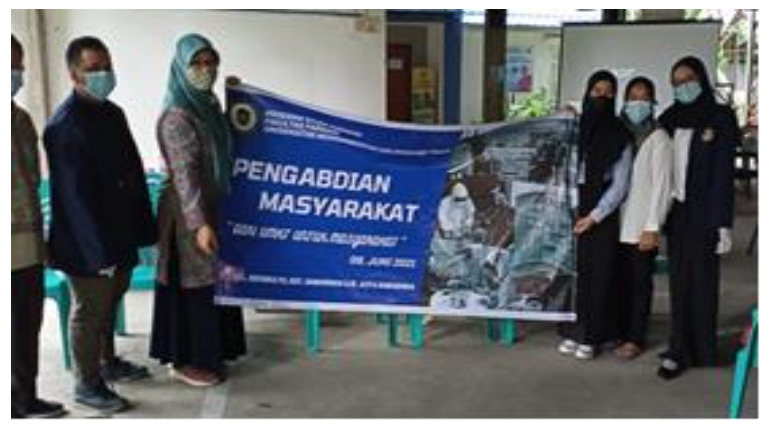

Gambar 1. Foto Bersama Ketua Kelompok Ibu-ibu PKK secara simbolis

Penyuluhan ini juga memberikan gambaran apoteker bisa menjadi salah satu alternatif layanan informasi obat, dalam rangka aplikasi swamedikasi. Penyuluhan juga menjelaskan tentang layanan informasi apa saja yang bisa didapatkan masyarakat dari apoteker. Kegiatan tersebut juga bisa menjadi acuan bagi masyarakat ketika bertanya pada apoteker meningkatkan kinerja tercapai efek terapi yang diharapkan serta meminimalkan risiko timbulnya efek samping obat yang tidak diharapkan (Putra et al., 2020).

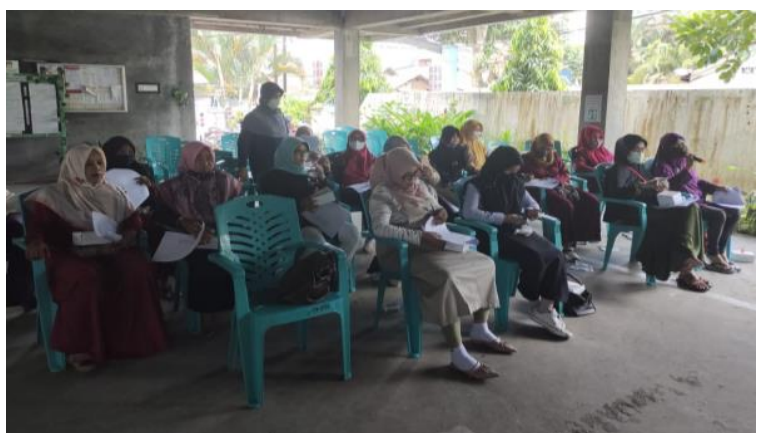

Gambar 2. Peserta Penyuluhan Mengisi Kuesioner dan Mendengarkan Materi Penyuluhan

Materi yang disampaikan juga meliputi keuntungan melakukan swamedikasi. Adapun keuntungan pengobatan swamedikasi yaitu kenyamanan dan kemudahan, tidak adanya biaya konsultasi, hemat waktu, penurunan beban kerja bagi sarana pelayanan kesehatan, lebih banyak waktu yang dapat digunakan untuk mengatasi pasien dengan penyakit berat, menghemat biaya kesehatan. Sedangkan, kerugian dari pengobatan swamedikasi yang utama adalah rentan terhadap penggunaan obat yang tidak rasional, seperti yang diketahui bahwa obat dapat menjadi racun terhadap tubuh jika penggunaannya tidak sesuai yang dapat menyebabkan pemborosan biaya dan waktu apabila salah menggunakan obat (Tandjung et al., 2021).

Pemberian materi tentang penggunaan obat herbal yang benar untuk swamedikasi juga menjadi informasi yang paling ditanyakan pada kegiatan pengabdian kepada masyarakat ini. Klasifikasi obat tradisional yang bisa diaplikasikan saat swamedikasi juga penting diberikan (Hardiana et al., 2019). Pembuatan obat tradisional dari bahan alam atau herbal juga butuh pengetahuan terkait dosis atau seberapa banyak tumbuhan yang diperlukan untuk mencapai efek terapi dalam suatu penyakit tertentu. Sedangkan, jenis obat tradisional yang dijual di apotek juga disampaikan agar peserta cermat dalam memilih obat.

Oleh karena itu, kegiatan pengabdian ini juga menggunakan pamflet sebagai media informasi tentang penggolongan obat (Gambar 3.). Ini bisa menjadi referensi dalam mengidentifikasi obat yang akan dikonsumsi selama swamedikasi. Agar tidak melakukan pengobatan yang berlebihan. 


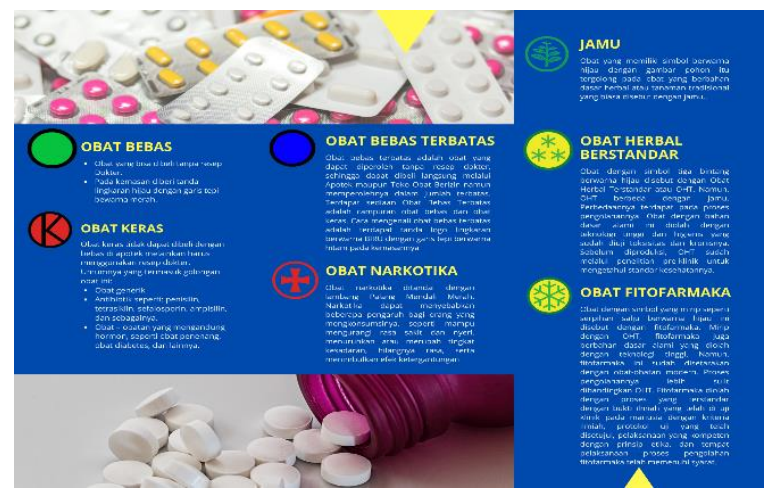

Gambar 3. Pamflet Penggolongan Obat sebagai Acuan Dalam Swamedikasi

Beberapa hal penting yang perlu diperhatikan dalam swamedikasi adalah pengetahuan dalam memahami gejala awal suatu penyakit. Hal ini juga diberikan penjelasan tersebut kepada peserta pengabdian kepada masyarakat. Jika terdapat diagnosis yang tidak sesuai, pengobatan yang berlebihan, indikasi penyakit yang tidak diberikan pengobatan, tidak dapat dilakukannya monitoring terapi, kehilangan kesempatan untuk konsultasi antara dokter dan pasien, berkurangnya peran dan pendapatan sarana pelayanan kesehatan, serta dapat menimbulkan adanya konflik kepentingan antara bisnis dan etika profesi. Pengetahuan tentang tingkatan keparahan suatu penyakit juga perlu dimiliki oleh pelaku swamedikasi, terutama ibu. Jika tidak mengetahui seberapa seriusnya atau parahnya suatu penyakit berdasarkan gejala yang ada, hal ini tentu menjadikan pengobatan yang dilakukan terlalu lama dan dapat memperparah gejala atau keluhan yang ada. Sehingga saat konsultasi ke dokter dan dilakukan pemeriksaan menyeluruh dokter harus memberikan obat golongan keras dengan dosis yang lebih tinggi untuk mengatasi penyakit tersebut (Abdulkadir \& Thomas, 2019; Suffah, 2017).

Peserta pengabdian kepada masyarakat menyadari pentingnya informasi yang telah diberikan dan antusia dalam bertanya pada sesi tanya jawab terkait materi dan pamflet yang telah dibagikan.

\section{Pengecekan Kesehatan}

Dari 30 peserta penyuluhan yang hadir terdapat 3 orang yang tidak berkenan untuk melakukan pengecekan gula darah. Hal tersebut dikarenakan peserta takut dengan proses pengambilan darah (Gambar 4.). Berdasarkan hasil pengecekan tersebut didapatkan data sebagian besar peserta penyuluhan mendapatkan nilai gula darah normal dengan angka persentase mencapai $77,7 \%$.

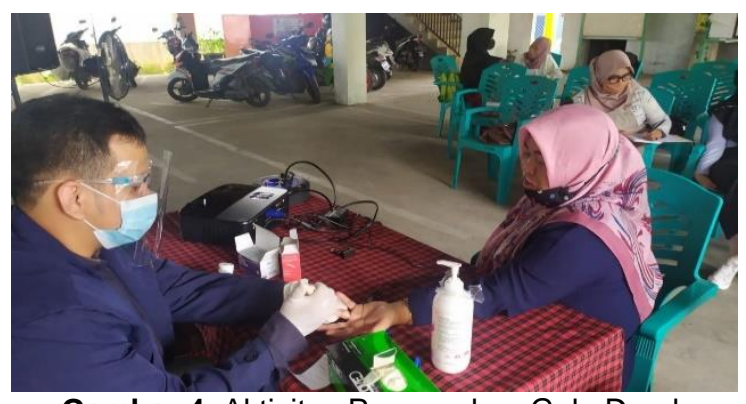

Gambar 4. Aktivitas Pengecekan Gula Darah

Sedangkan dari 30 peserta penyuluhan yang hadir terdapat 1 orang yang tidak melakukan cek tekanan darah. Berdasarkan katagori tekanan darah yang bersumber dari Kementerian Kesehatan Republik Indonesia (S. Nita, 2018), didapatkan hasil 89,6\% peserta penyuluhan mendapatkan nilai tekanan darah normal (Gambar 5.)

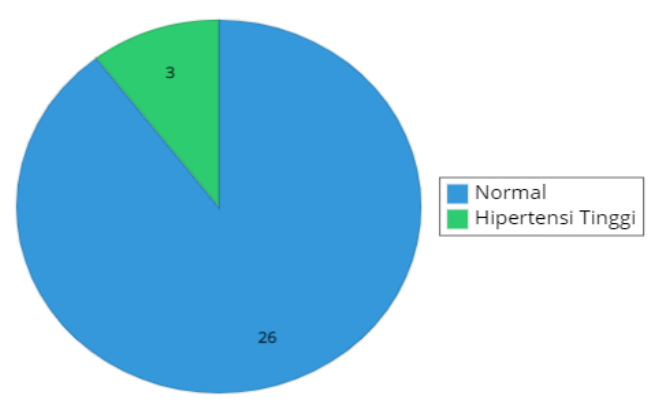

Gambar 5. Persentase Pengecekan Tekanan Darah

Antusias peserta penyuluhan pada saat pemeriksaan tekanan darah pada Gambar 6 . disertai beberapa pertanyaan seputar pola makan, konsultasi obat bersama apoteker, dan pengalaman swamedikasi peserta. Sebagian besar ibu PKK menerapkan pola makan sehat dan olahraga ringan secara teratur.

Pengecekan kesehatan ini jika dilakukan secara berkala diharapkan bisa menjadi kontrol pencegahan penyakit degeneratif dan komorbid covid (Anisa et al., 2021). Perilaku pola makan sehat dan olahraga terbukti dapat mempengaruhi kadar gula darah ((Item et al., 2021; Saviqoh \& Hasneli, 2021). Pola hidup sehat dan olahraga juga menjadi aspek penting mencegah penyakit hipertensi (Farman et al., 2021; Rachmawati et al., 2021) 


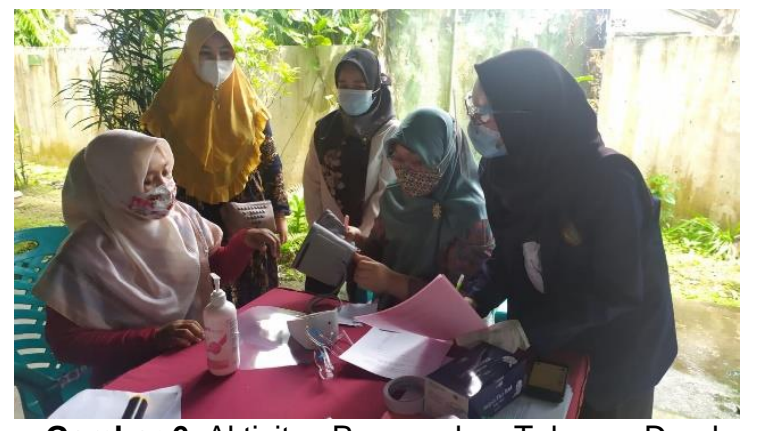

Gambar 6. Aktivitas Pengecekan Tekanan Darah

Kegiatan pengabdian kepada masyarakat ini telah berhasil dilaksanakan. Berdasarkan angket evaluasi kegiatan, peserta penyuluhan merasakan manfaat dari pemberian edukasi swamedikasi di masa pandemi, lebih memahami tahapan penting dalam swamedikasi dan diharapkan akan ada kegiatan serupa secara berkala.

\section{SIMPULAN DAN SARAN}

Tingkat pengetahuan ibu-ibu PKK tentang swamedikasi dapat dipengaruhi dari lingkungan dan latar belakang masyarakat itu sendiri. Namun, pengetahuan tentang tahapan dan konsep swamedikasi masih sedikit. Setelah diberikan penyuluhan, tingkat pemahaman peserta meningkat, tidak hanya sebatas pengertian swamedikasi saja. Sedangkan dari hasil pemeriksaan kesehatan, sebagian besar peserta penyuluhunan memiliki kadar glukosa darah yang normal dan tekanan darah yang normal. Berdasarkan wawancara, hal tersebut kemungkinan dipengaruhi oleh gaya hidup sehat dan rajin berolahraga.

Peserta penyuluhan merasakan manfaat dari penyuluhan ini dapat memberikan pengetahuan penting ibu yang diperlukan dalam dalam merawat anggota keluarga. Disarankan untuk melakukan kegiatan penyuluhan secara berkala untuk memaksimalkan peran ibu dalam kegiatan pengabdian masyarakat selanjutnya.

\section{UCAPAN TERIMAKASIH}

Penghargaan kami sampaikan kepada aparat Kelurahan Sidomulyo yang telah membantu dalam memfasilitasi tempat kegiatan dan kepada Program Studi Farmasi, Fakultas Farmasi, Universitas Muhammadiyah Kalimantan Timur yang telah mendanai untuk kegiatan ini.

\section{DAFTAR RUJUKAN}

Abdulkadir, W., \& Thomas, N. (2019). Laporan Pengabdian Masyarakat (Vol. 1, Issue 1).
Anisa, Thahir, R., Magfirah, N., Baharullah, \& Ernawati. (2021). Counseling and Health Checks as an Effort to Prevent Degenerative Diseases. JCES (Journal of Character Education Society), 4(1), 221228.

Candradewi, S. F., \& Kristina, S. A. (2017). Gambaran Pelaksanaan Swamedikasi dan Pendapat Konsumen Apotek Mengenai Konseling Obat Tanpa Resep Di Wilayah Bantul. Pharmaciana, 7(1), 41. https://doi.org/10.12928/pharmaciana.v7i1. 5193

Dianawati, O., Fasich, \& Athijah, U. (2008). Hubungan Persepsi Terhadap Iklan di Televisi Dengan Perilaku Swamedikasi Pelajar SMU Negri di Surabaya. Majalah Farmasi Airlangga, 6(1), 10-16.

Endang, T. (2014). Pelayanan Keperawatan Bagi Penderita Hipertensi Secara Terpadu. Graha IImu.

Farman, D., Reza, S., Sunthree, G. M., \& Patimah, S. S. (2021). Pengaruh Senam Lansia Terhadap Perubahan Tekanan Darah Pada Penderita Hipertensi. Jurnal Penelitian Perawat Profesional, 3(2), 347358.

http://jurnal.globalhealthsciencegroup.com/ index.php/JPPP/article/download/83/65

Hardiana, H., Rasnovi, S., \& Zumaidar, Z. (2019). Use of Plants As Traditional Medicine in Swamedication in Pidie Communities. Jurnal Natural, 19(2), 35-41. https://doi.org/10.24815/jn.v19i2.13192

Husni, S. M., \& Rahayu, P. (2020). Description of Parent's Knowledge About Swamedication Of Diarrhea In Children In Rangkapanjaya Baru Depok City. FARMASI-QU, Jurnal Kefarmasian, Akademi Farmasi Bhumi Husada Jakarta., 7(1), 46-56.

Item, D. R., Dary, \& Mangalik, G. (2021). Jurnal Keperawatan \& Kebidanan Jurnal Keperawatan \& Kebidanan. Jurnal Keperawatan, 13(1), 213-226.

Kurniasih, K. A., Supriani, S., \& Yuliastuti, D. (2020). Analisis Faktor Tingkat Pengetahuan Masyarakat Tentang Tindakan Swamedikasi Diare. Media Informasi, 15(2), 101-105. https://doi.org/10.37160/bmi.v15i2.321

Mardiati, N., Islamiah, R., \& Fitriah, R. (2021). Pengaruh Iklan Obat Flu Di Televisi Terhadap the Effect of Flu Drug Advertising on Television. Jurnal Riset Kefarmasian Indonesia, 3(1).

Nita, S. (2018). Ketidakpatuhan Pola Makan pada 
Volume 4, Nomor 3, Agustus 2021. p-ISSN : 2614-5251

e-ISSN : 2614-526X

Pasien Hipertensi di Kota Malang. Universitas Muhammadiyah Malang.

Nita, Y., Athijah, U., Wijaya, I. N., Ilahi, R. K., \& Hermawati, M. (2008). Kinerja Apotek dan Harapan Pasien Terhadap Pemberian Informasi Obat Pada Pelayanan Swamedikasi di Beberapa Apotek di Surabaya. Majalah Farmasi Airlangga, 6(2), 41-45.

Putra, O. K. I. N., Kresnamurti, A., \& Yunita, A. (2020). Tingkat Kepuasan Pasien Swamedikasi Terhadap Pelayanan Informasi Obat di Apotek Pesisir Surabaya Timur ( Satisfaction Level of Patients with Self Medication on Drug Information Services in Several Pharmacies of East Surabaya ). 18(2), 143-149.

Rachmawati, D., Sintowati, R., Lestari, N., \& Agustina, T. (2021). Pengaruh Diet Dash (Dietary Approach To Stop Hypertension) Terhadap Penurunan Tekanan Darah Pada Penderita Hipertensi: Studi Literatur. Proceeding of The URECOL, 150-157.

Restiyono, A. (2016). Analisis Faktor yang Berpengaruh dalam Swamedikasi Antibiotik pada lbu Rumah Tangga di Kelurahan Kajen Kebupaten Pekalongan. Jurnal Promosi Kesehatan Indonesia, 11(1), 1427. https://doi.org/10.14710/jpki.11.1.14-27

Saputra, M. R., Yuniarti, E., \& Sumarmin, R. (2018). Pengaruh Ekstrak Daun Sirih Mersh (Piper crocatum Ruiz \& Pav.) Terhadap Glukosa Darah Mencit (Mus musculus L.) Jantan yang Diinduksi Sukrosa. EKSAKTA: Berkala IImiah Bidang MIPA, 19(1), 43-55.

Saviqoh, I. D., \& Hasneli, Y. (2021). Analisis Pola Hidup dan Dukungan Keluarga Pada Pasien. Health Care: Jurnal Kesehatan, 10(1), 181-193.

Setiati, S., \& Azwar, M. K. (2020). COVID-19 and Indonesia. April.

Suffah, N. K. (2017). Pengaruh Tingkat Pengetahuan Terhadap Tindakan

Swamedikasi Diare Di Kecamatan Karanggeneng Lamongan. Universitas Islam Negeri Maulana Malik Ibrahim.

Tandjung, H., Wiyono, W. I., \& Mpila, D. A. (2021). Pengetahuan Dan Penggunaan Antibiotik Secara Swamedikasi Pada Masyarakat Di Kota Manado. Pharmacon, 10(2), 780. https://doi.org/10.35799/pha.10.2021.3404 4

Yarza, H. L., Yanwirasti, Y., \& Irawati, L. (2015). Hubungan Tingkat Pengetahuan dan Sikap dengan Penggunaan Antibiotik Tanpa
Resep Dokter. Jurnal Kesehatan Andalas, 4(1), https://doi.org/10.25077/jka.v4i1.214

Yusuf, M., Widodo, S., \& Raka Irwansyah, A. (2021). Analisa Tingkat Pengetahuan Dan Perilaku Terhadap Penggunaan Obat Influenza Dan Batuk Secara Swamedikasi Di Desa Muara Burnai I Kabupaten Ogan Komering llir. JFL: Jurnal Farmasi Lampung, $\quad$ 9(2), 125-130. https://doi.org/10.37090/jl.v9i2.341 